\title{
Bone mineral density study with DXA in asthmatic children
}

\author{
Sameh Ahmad Khodair ${ }^{1, ~ *, ~ O m a r ~ A h m e d ~ H a s s a n e n ~}{ }^{2}$, Usama Elsaie Ghieda ${ }^{2}$, \\ Sameh Abdallah Abdelnaby ${ }^{3}$
}

${ }^{1}$ Radiology Department, Faculty of Medicine, Tanta University, Egypt

${ }^{2}$ Radiology Department, Faculty of Medicine, Tanta University, Egypt

${ }^{3}$ Pediatric Department, Faculty of Medicine, Minoufia University, Egypt

\section{Email address:}

samehkhodair@gmail.com (S. A. Khodair), omarhassanien@yahoo.com (O. A. Hassanen), usama_ghieda@yahoo.com (U. E. Ghieda), samehabdallah@yahoo.com (S. A. Abdelnaby)

\section{To cite this article:}

Sameh Ahmad Khodair, Omar Ahmed Hassanen, Usama Elsaie Ghieda, Sameh Abdallah Abdelnaby. Bone Mineral Density Study with DXA in Asthmatic Children. American Journal of Sports Science. Vol. 1, No. 3, 2013, pp. 51-55. doi: 10.11648/j.ijmi.20130103.13

\begin{abstract}
Objective: the aim of this work is to assess the effect of asthma and its therapy on bone mineral density in children. Patients and methods: thirty asthmatic children and adolescent, their ages ranged from 7-15 years and 15 apparently healthy age and sex matched children were enrolled in the study. All asthmatic patients were on inhaled corticosteroid therapy for at least 6 months duration. Patients and controls were subjected to full history taking, meticulous clinical examination and laboratory investigations; including serum calcium, phosphorus and alkaline phosphatase. Determination of bone minerals density of the lumbar spine by dual energy X-ray absorpiometry (DXA) method at L2 - L4 levels of lumbar vertebrae. Results: showed that height was higher among controls (143.5 \pm 12 ) compared to patients $(133.6 \pm 11)$ with statistical significant difference. The study revealed that patients had lower bone mineral density $(0.61 \pm 0.11)$ and lower $z$-score $(-2.08 \pm 0.5)$ when compared to control $(0.69 \pm 0.13)$ and $(-1.4 \pm 1.8)$ respectively with statistically significant difference $\mathrm{P}<0.05$. Conclusion: Bone mineral density was reduced in asthmatic children.
\end{abstract}

Keywords: Bone Mineral Density, DXA Scan, Bronchial Asthma, Children

\section{Introduction}

Asthma is the most frequent chronic disease during childhood in developed countries. In the United States, it is the most common chronic disease of childhood [1]. World wide, childhood asthma appears to be increasing in prevalence, despite considerable improvements in management [2].

Chronic inflammation is a well known cause of growth retardation and other metabolic effects such as a reduction of bone mineral density[3]. New advances in understanding of the pathophysiology of asthma have made us aware of the inflammatory nature of this disease, inflammation is present even in patients with mild disease and, hence, the early use of inhaled corticosteroids (ICS) has been advocated for optimal treatment of bronchial asthma [4]. Inhaled corticosteroids are first line anti-inflammatory therapy in asthma management [5].

There is many factors affecting bone mineral density (BMD) in children, these include diet, physical activity, growth, genetic predisposition and chronic disease such as bronchial asthma [6].

In addition to these factors, long term systemic steroid therapy in asthmatic patients is associated with decreased trabecular bone density and osteoporosis has been found to occur in $10-40 \%$ of patients [7].

The use of ICS in adult patients, play a part in the development of osteoporosis. It is, however, known that the magnitude of the effect of ICS on mineral metabolism is significantly less than that of therapeutically equivalent doses of oral steroids [8]. Asthmatic children experience a prepubertal growth retardation and delayed onset of puberty, hence, the growth and puberty are very important for increase in bone mineral density, they also might have reduction in BMD [9].

\section{Patients and Methods}

This case control study was carried out on 30 patients with bronchial asthma, their ages ranged from 7-15 years 
and 15 apparently healthy age and sex matched children from the period of April 2012 to September 2013.

Inclusion criteria; children seven years old or more up to 15 years with history of bronchial asthma diagnosed and classified according to GINA guideline [10] into four categories:

I. Mild intermittent asthma, (patients had symptoms less than once a week, brief exacerbations, nocturnal symptoms not more than twice a month and peak expiratory flow (PEF) or forced expiratory volume in 1 second (PEV1) $<20 \%$ ).

II. Mild persistent asthma, (patients had symptoms more than once a week but less than once a day, exacerbation may affect activity and sleep, nocturnal symptoms more than twice a month and PEF or FEV1 variability $<20$ $30 \%$ ).

III. Moderate persistent asthma, (patients had symptoms daily, exacerbation may affect activity and sleep, nocturnal symptoms more than once a week, daily use of inhaled short-acting (32 agonist, PEF or FEV1, variability $>30 \%$ and FEV1 $60-80 \%$ predicated).

IV. Severe persistent asthma like patient with moderate persistent asthma, but FEV1 60\% predicated.

All asthmatic patients in this study were using ICS for at least 6 months duration. Children less than 7 years old or asthmatic patients with other chronic disease or not receiving ICS were excluded from the study.

All patients and controls were subjects to the following after written consent, from their parents. Thorough history taking; with special emphasis on age, sex, disease onset and duration, symptoms of exacerbation of asthma, grading of asthma severity type, mode, dose and duration of inhaled steroid therapy and degree of asthma control. Clinical examination of patients and control with particular emphasis on height, weight and mid parental height. Laboratory investigations; including serum calcium, phosphorus and bone alkaline phosphatase.

Determination of BMD of the lumbar spine by dual energy X-ray absorpiometry (DXA) method at L2-L4 levels of lumbar vertebrae for cases and controls.

\subsection{Technical Aspect and Performance of DXA}

The method used to determine BMD of lumbar spine was dual energy X-ray absorpiometry densitometry (Prodigy, GE Medical System Lunar). The densitometer was calibrated daily using phantom of known density. The measuring site from L2-L4 vertebrae in anteroposterior projection; the scanning was taken in the supine position with the knees flexed and calves resting on cushion to separate the spinous processes and to prevent the overlaps of bone structure. The lumbar spine was straight and centered in the image, as well as visualization of the last rib pair and also the upper sacrum. The region of interest (ROI) is generated automatically using edge detection software and was selected from the L1 to L4 vertebral bodies. These regions were included the entire vertebral body with a minimum of adjacent soft tissue The scanning time was 2-4 minutes and the radiation dose was less than $3 \mathrm{mREM}$ which is about one tenth of the exposure for standards chest X-ray.

The graph displayed by the computer shows the following; the mean value of BMD expressed in $\mathrm{gm} / \mathrm{cm}^{2}$, the calculated values of BMD can be compared to age and sex-matched normal population (Z-score) for age of patients ranges from 5-20 years. Kanis, et al,[11] classified patients into; osteoporotic, BMD values $<-2.5 \mathrm{SD}$ below the mean, osteopenic, with BMD values $<-1$ and $>-2.5 \mathrm{SD}$ below the mean and normal BMD, with values in the range of mean \pm 1 SD.

All patients and control group submitted to Plain $\mathrm{X}$ - ray of the both hands and skeletal age was determined.

Statistical analysis: Mann-Whitney U test, and Paired t - test was used to test for differences between the normal control and patients, $p$ value of $<0.05$ was considered statistically significant. All statistics were performed using Minitab Ver.16 (Minitab Inc. USA).

\section{Results}

Thirty asthmatic children and adolescent their ages ranged 7-15 years and 15 healthy age and sex matched children were included in this work.

Our results revealed that height was higher among controls $(143.5 \pm 12)$ compared to patients $(133.6 \pm 11)$ with statistically significant difference $<0.05$. The bone age was much delayed among studied cases $(9 \pm 2.4)$ compared to controls $(10.4 \pm 1.9)$ with statistically significant difference $\mathrm{p}<0.05$

Regarding to other general data (sex, chronological age and weight) and laboratory data (serum calcium, phosphorus and alkaline phospatase); there was no statistical significant difference between both groups (patients and controls) (table1) .

Table (1). Statistical comparison between patients and controls as regard to general and laboratory data

\begin{tabular}{lcccc}
\hline \multicolumn{1}{c}{ Variables } & $\begin{array}{c}\text { Cases } \\
\text { no=30 }\end{array}$ & $\begin{array}{c}\text { Controls } \\
\mathbf{n = 1 5}\end{array}$ & $\begin{array}{c}\text { Test of } \\
\text { significance }\end{array}$ & P value \\
\hline $\begin{array}{l}\text { Age (year) Range } \\
\text { Mean } \pm \text { SD }\end{array}$ & $\begin{array}{c}7-15 \\
10.3 \pm 1.8\end{array}$ & $\begin{array}{c}7.4-14 \\
10.2+1.9\end{array}$ & $\mathrm{~T}=0.4$ & $>0.05$ \\
Sex & $12(40 \%)$ & $7(46.7 \%)$ & $\mathrm{X}^{2}=0.4$ & $>0.05$ \\
Male & $18(60 \%)$ & $8(53.3 \%)$ & & \\
$\begin{array}{l}\text { Female } \\
\text { Weight Kg mean } \pm\end{array}$ & $32.3+12$ & $37.8+11$ & 1.5 & $>0.05$ \\
$\begin{array}{l}\text { SD } \\
\text { Height (cm) } \\
\text { mean } \pm \text { SD }\end{array}$ & $133.6+11$ & $143.5 \pm 12$ & 2.1 & $<0.05$ \\
$\begin{array}{l}\text { Bone age } \\
\begin{array}{l}\text { Serum calcium } \\
\text { mg/dl }\end{array}\end{array}$ & $9 \pm 2.4$ & $10.4 \pm 1.9$ & 2.5 & $<0.05$ \\
$\begin{array}{l}\text { Serum } \\
\text { phosphorus mg/dl }\end{array}$ & $4.6 \pm 0.4$ & $4.5 \pm 0.3$ & 1.8 & $>0.05$ \\
$\begin{array}{l}\text { Alkaline } \\
\text { phsophatase }\end{array}$ & $222.2+63$ & $224 \pm 58$ & 0.3 & $>0.05$ \\
\hline
\end{tabular}


The study demonstrated that $46.7 \%$ of cases had normal bone age and $36.7 \%$ had delayed bone age seen more in males, while $16.6 \%$ had advanced bone age and most of them were females, and only one female among controls had advanced bone age ( table 2 )

Table (2). Wrist X-ray finding (bone age) of the cases and controls.

\begin{tabular}{|c|c|c|c|c|c|c|c|c|c|c|c|c|}
\hline \multirow{3}{*}{$\begin{array}{l}\text { Bone age } \\
\text { (years) }\end{array}$} & \multirow{3}{*}{ No } & \multicolumn{3}{|c|}{ Normal } & \multirow{3}{*}{ No } & \multicolumn{3}{|c|}{ Delayed } & \multicolumn{4}{|c|}{ Advanced } \\
\hline & & \multirow{2}{*}{0} & \multicolumn{2}{|c|}{ Gender } & & \multirow{2}{*}{$\%$} & \multicolumn{2}{|c|}{ Gender } & \multirow{2}{*}{ No } & \multirow{2}{*}{$\%$} & \multicolumn{2}{|c|}{ Gender } \\
\hline & & & M & $\mathrm{F}$ & & & M & $\mathrm{F}$ & & & M & $\mathrm{F}$ \\
\hline$=30$ & 14 & 46.7 & 5 & 9 & 11 & 36.7 & 6 & 5 & 5 & 16.6 & 1 & 4 \\
\hline $\begin{array}{l}\text { Controls } \\
\mathrm{n}=15\end{array}$ & 14 & 93.3 & 7 & 7 & 0 & 0 & 0 & 0 & 1 & 6.7 & - & 1 \\
\hline
\end{tabular}

The results showed that patients, had lower BMD $(0.61 \pm 0.1)$ when compared to controls $(0.69 \pm 0.13)$ with statistically significant difference, also the patients had lower Z-score $(-2.08 \pm 0.5)$ than controls $(-1.4 \pm 1.8)$ with statistically significant difference $\mathrm{P}<0.05$. (table3)

Table (3). Statistical comparison between patients and controls as regard BMD $\mathrm{gm} / \mathrm{cm} 2$ and matched age Z-score

\begin{tabular}{lcccc}
\hline \multicolumn{1}{c}{ Variables } & $\begin{array}{c}\text { Cases } \\
\mathbf{n o}=\mathbf{3 0}\end{array}$ & $\begin{array}{c}\text { Controls } \\
\mathbf{n = 1 5}\end{array}$ & $\begin{array}{c}\text { Test of } \\
\text { significance } \mathbf{~}\end{array}$ & P value \\
\hline BMDgm $/ \mathrm{cm}^{2}$ & $0.47-0.79$ & $0.55-0.84$ & & \\
$\begin{array}{l}\text { Range Mean } \pm \\
\text { SD }\end{array}$ & $0.61 \pm 0.11$ & $0.69 \pm 0.13$ & 2.1 & $<0.05$ \\
$\begin{array}{l}\text { Iatched age Z- } \\
\text { score }\end{array}$ & & & & \\
$\quad$ Range & $-3.0--0.7$ & $-1.6--1$ & 2.2 & $<0.05$ \\
Mean \pm SD & $-2.08 \pm 0.5$ & $-1.4 \pm 1.8$ & & \\
\hline
\end{tabular}

\section{Discussion}

Asthma is the most common chronic disease in children; it is worldwide problem that affects approximately 100 million people worldwide [12]. During the past several decades, this prevalence has been increasing by $5-6 \%$ per year reaching rates of $30-40 \%$ in many countries. Therefore it is important to assess the impact of such wide world illness and its treatment regarding efficacy and safety [13].

Growth and puberty are very important for increase in bone mineral density, therefore factors that affect growth in asthmatic patient can lead to reduction of BMD. These include severity and duration of illness, hypoxemia, recurrent respiratory infection, age at onset of the disease and frequency of hospitalization. In addition to demographic and social factors such as age of the child mother's, education, hormonal, nutritional, and psychological factors. The most important factors, however, may be asthma severity and treatment with exogenous corticosteroids [14].

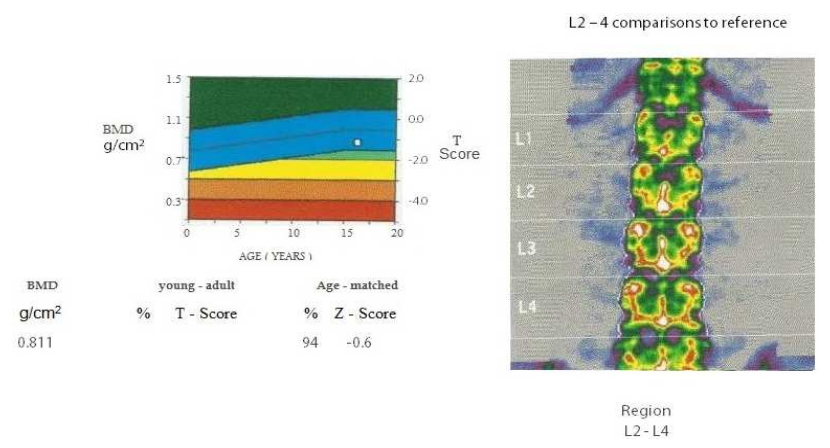

Figure 1. A female healthy control aged 15 years old shows $B M D=$ $0.8111 \mathrm{gm} / \mathrm{cm}^{2}$ and age - matched Z-score $=-0.6$

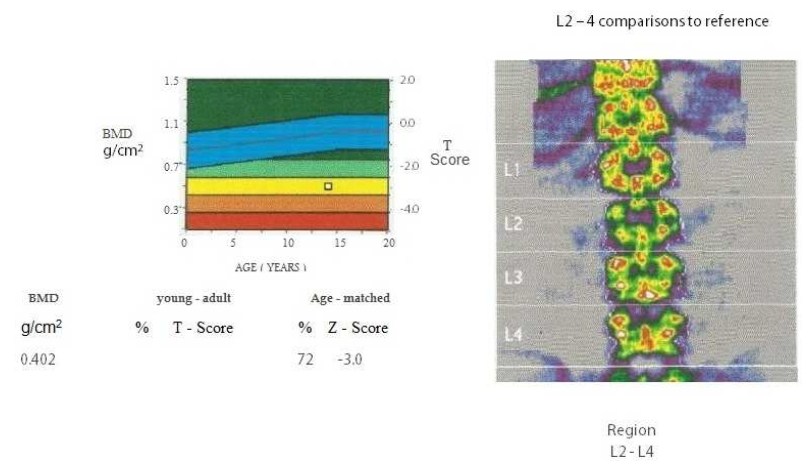

Figure 2. A male asthmatic patient aged 13 years old, under ICS more than one year shows $B M D=0.402 \mathrm{gm} / \mathrm{cm}^{2}$ and age matched Z-Score = $-3.0$

Children with chronic asthma start to show growth retardation at the age of 10 years which is most marked at the age of 14 years. At 10 years age, the retardation is mainly in height but at 14 years it is both height and weight [15].

Peak bone density attained during childhood may be critical determinant of risk of fracture in adulthood. For this reason it is important to fully understand the factors influencing peak bone mineral density in children. These include diet, physical activity, growth and genetic predisposition [16]. Some chronic diseases have also been reported to be associated with reduced peak bone mass in children [17].

In this study, the height in patients group (133.6 111$)$ was significantly lower than in controls group (143.5 \pm 12$)$. Comparing weight in both groups was statistically insignificant. Bone age was significantly much delayed among studied cases $(9 \pm 2.4)$ compared to controls $(10.4+1.9)$. A study carried out by Ismail et al. [18] showed no significant major effect of asthma on physical growth, a part from skeleton maturation (bone age), which was found to be significantly retarded in asthmatic, compared to normal children.

Growth suppression in asthmatic patients particularly those with poor control may depend on long-term catabolic stress and severe sleep disturbances interfering with the diurnal secretion of anabolic hormones [19]. On the contrary to our results, Agertaft and Pedersen [20] found no difference in bone age among patients and controls. 
Patients group in our study had lower BMD than controls group, this agrees with Mentzel et al. [21] who stated that reduced bone mineral density is a possible complication of bronchial asthma and this finding consistent with observation of Ruegsegger et al. [22] who found that the BMD of asthmatic patients never having received inhaled or oral corticosteroid tended to be lower than the values of healthy controls.

Asthma itself, does not pose a threat to bone health. However medications used as ICS, and some behaviors as milk free diets and poor exercise triggered by concern over the disease can have negative impact on the bone mineral density. This is done by uncoupling the link between bone formation and resorption by both suppressing bone formation and increasing bone resorption [23].

A study carried out by Baraldi et al.[24] was noted that slightly reduced gain in bone mass in asthmatic patients treated by ICS for 6 months. Also our results in accordance with Griffiths et al. [25] who reported reduced BMD estimated by DXA in $16.2 \%$ of their patients with asthma treated by prolonged ICS. However our finding disagree with Agretoft and Pedersen [20] as they concluded that long term treatment with ICS at an average daily dose of $504 \mathrm{mg}$ has no detectable adverse effect on BMD in children with chronic asthma.

Regarding to $\mathrm{Z}$ score it was found to be significantly lower among patients group in comparison to controls group, this was in accordance with Mentzel et al. [26] who found that $\mathrm{Z}$ score was reduced at a level of $<-1.0 \mathrm{SD}$ in $23.5 \%$ of cases (4/17 patient with asthma).

It is known that during steroid therapy bone loss occurs mainly at sites in the skeleton where there is a high concentration of trabecular bone, such as the spine and ribs [9].

Trabecular bone is in fact for more metabolically active than cortical bone, the mid lumbar spine, therefore, is an ideal site for monitoring metabolic bone disease such as osteoporosis [27]. For this reason, we decided to use DXA. This method offers the advantage of being the safest method currently available for the in vivo quantization of $\mathrm{BMD}$, and it has been shown to be a precise and accurate technique from the newborn to the adult [3].

Because of low irradiation exposure and high precision, DEXA is to be considered a non invasive method which is well adapted to the child, and would be useful to define those patients at higher risk such as growing children[28].

\section{Conclusion}

Bone mineral density may be reduced in asthmatic children either due to asthma itself and/or long-term inhaled corticosteroids. We recommend that use of inhaled corticosteroid at the lowest effective dose to avoid reduction of bone mineral density and to use the simple, safe and noninvasive dual energy X-ray absorpiometry technique for determination of BMD in children.

\section{References}

[1] Rodehorst-Weber, T.K., et al., Screening Native American children for asthma: findings from focus group discussions. Issues Compr Pediatr Nurs, . 2009. 32(4): p. 200-9.

[2] Marks, G.B., Environmental factors and gene-environment interactions in the aetiology of asthma. Clin Exp Pharmacol Physiol, . 2006. 33(3): p. 285-9..

[3] Konig, P., et al., Bone metabolism in children with asthma treated with inhaled beclomethasone dipropionate. J Pediatr, . 1993. 122(2): p. 219-26.

[4] Juniper, E.F., et al., Effect of long-term treatment with an inhaled corticosteroid (budesonide) on airway hyperresponsiveness and clinical asthma in nonsteroiddependent asthmatics. Am Rev Respir Dis, . 1990. 142(4): p. 832-6.

[5] Rabinovitch, N. and E.W. Gelfand, New approaches to the treatment of childhood asthma. Curr Opin Pediatr, . 1998. 10(3): p. 243-9.

[6] Mardon, J., et al., Dietary protein supplementation increases peak bone mass acquisition in energy-restricted growing rats. Pediatr Res, . 2009. 66(5): p. 513-8.

[7] Grzanka, A. and J. Jarzab, [Nongenomic effects of glucocorticoids, an important mechanism of inhaled glucocorticoids action in asthma]. Pneumonol Alergol Pol, . 2009. 77(5): p. 453-9.

[8] Hodsman, A.B., et al., Differential effects of inhaled budesonide and oral prednisolone on serum osteocalcin. $\mathrm{J}$ Clin Endocrinol Metab, . 1991. 72(3): p. 530-40.

[9] Geusens, P., et al., Heterogeneity of growth of bone in children at the spine, radius and total skeleton. Growth Dev Aging, . 1991. 55(4): p. 249-56.

[10] Bateman, E.D., et al., Global strategy for asthma management and prevention: GINA executive summary. Eur Respir J, . 2008. 31(1): p. 143-78.

[11] Kanis, J.A., J.P. Devogelaer, and C. Gennari, Practical guide for the use of bone mineral measurements in the assessment of treatment of osteoporosis: a position paper of the European foundation for osteoporosis and bone disease. The Scientific Advisory Board and the Board of National Societies. Osteoporos Int, . 1996. 6(3): p. 256-61.

[12] Kemp, J.P., Advances in the management of pediatric asthma: a review of recent FDA drug approvals and label updates. J Asthma, . 2005. 42(8): p. 615-22.

[13] Amado, M.C. and J.M. Portnoy, Recent advances in asthma management. Mo Med, . (2006):103 (1) p. 60 -4.

[14] Wolthers, O.D., Impact of inhaled and intranasal corticosteroids on the growth of children. BioDrugs, . 2000. 13(5): p. 347-57.

[15] Doull, I.J., The effect of asthma and its treatment on growth. Arch Dis Child, . 2004. 89(1): p. 60 - 3.

[16] Valimaki, M.J., et al., Exercise, smoking, and calcium intake during adolescence and early adulthood as determinants of peak bone mass. Cardiovascular Risk in Young Finns Study Group. BMJ, . 1994. 309(6949): p. 230-5. 
[17] Albanese, A. and R. Stanhope, Investigation of delayed puberty. Clin Endocrinol (Oxf), . 1995. 43(1): p. 105-10.

[18] Ismail, N.F., et al., Study of growth in prepubertal asthmatics. Indian J Pediatr, . 2006. 73(12): p. 1089 - 93.

[19] Chen, C.M., W. He, and S.Y. Chang, [The changes of the attributable factors of child growth]. Wei Sheng Yan Jiu, . 2006. 35(6): p. 765-8.

[20] Agertoft, L. and S. Pedersen, Bone mineral density in children with asthma receiving long-term treatment with inhaled budesonide. Am J Respir Crit Care Med, . 1998. 157(1): p. 178-83.

[21] Mainz, J.G., et al., Cross-sectional study on bone densityrelated sonographic parameters in children with asthma: correlation to therapy with inhaled corticosteroids and disease severity. J Bone Miner Metab, . 2008. 26(5): p. 48592.

[22] Ruegsegger, P., T.C. Medici, and M. Anliker, Corticosteroidinduced bone loss. A longitudinal study of alternate day therapy in patients with bronchial asthma using quantitative computed tomography. Eur J Clin Pharmacol, . 1983. 25(5): p. $615-20$.
[23] Cormier, C., J.C. Souberbielle, and A. Kahan, DHEA in bone and joint diseases. Joint Bone Spine, . 2001. 68(6): p. $588-94$.

[24] Baraldi, E., et al., Effect of beclomethasone dipropionate on bone mineral content assessed by X-ray densitometry in asthmatic children: a longitudinal evaluation. Eur Respir J, . 1994. 7(4): p. $710-4$.

[25] Griffiths, A.L., et al., Effect of high-dose fluticasone propionate on bone density and metabolism in children with asthma. Pediatr Pulmonol, . 2004. 37(2): p. 116-21.

[26] Mentzel H. Mainz J, S.M., Malich I, Boettecher J, and Kaiser WA, Peripheral bone status in children with asthma evaluated by digital X-ray radiogrammetry. The internet Journal of Radiology . 1996. 5(1): p. 1528-8404.

[27] Ponder, S.W., et al., Spinal bone mineral density in children aged through . years. Am J Dis Child, . 1990. 144(12): p. 1346-8.

[28] Kreipe, R.E., Bones of today, bones of tomorrow. Am J Dis Child, . 1992. 146(1): p. 22-5. 